\title{
Evaluating the quality of long-term care services in the city of La Plata, Argentina.
}

Peter Lloyd-Sherlock (corresponding author)

School of International Development

University of East Anglia

Norwich

NR4 7HT

UK

p.lloyd-sherlock@uea.ac.uk.Tel. 441603592327

Bridget Penhale, School of Health Sciences, University of East Anglia, UK.

Nelida Redondo, SIDOM Foundation, Argentina.

Full ethical approval was obtained from the relevant committee of the University of East Anglia.

\section{Abstract}

This paper reports on an innovative survey of long-term care (LTC) facilities for older people in the Argentine city of La Plata. It applies a range of qualitative methodologies, including a clandestine audit conducted by older people living in the community. The paper pays particular attention to the types and availability of services, perceived quality and the rigour of regulatory processes. It finds that there has been a rapid growth in the availability of formal services, but that there are many gaps in provision, especially for older people with complex care needs. There are strong indications that service quality is uneven and, in some cases, this amounts to the contravention of basic human rights. State regulation is hampered by institutional fragmentation and weak governance. A wider set of expert 
interviews and the limited available published information indicate that these findings are unlikely to be exceptional, and that similar issues affect rapidly-emerging LTC systems in many low and middle-income countries.

\section{Key words}

Older people; long-term care; quality; Latin America

Declarations of interest: none. 


\section{Introduction}

This paper examines the quality of long-term care (LTC) services in a single Argentine city, including services provided in both residential and community settings. The paper assesses the capacity of state agencies and other actors to monitor and regulate standards. Applying an innovative research design, the paper reveals significant gaps in provision, as well as widespread shortcomings in quality and regulation. Taken as a whole, this study provides the most detailed published analysis of LTC quality in any low or middle-income country (LMIC) setting.

In Argentina as elsewhere, LTC for older people is mainly provided by female family members, without remuneration or external support from states or other agencies (LloydSherlock, et al 2017). There is, however, evidence that provision of more organised forms of provision is growing rapidly. For example, in 2010 Argentina's Union of Gerontological Service Providers estimated the country contained 6,000 residential care homes. ${ }^{1}$ Research on LTC services in all LMICs remains very limited, but there are indications that formal services are evolving quickly, often in haphazard, unplanned and uncoordinated ways (WHO, 2015). ${ }^{2}$ This raises concerns about service quality and the wellbeing of caredependent older people. At worst, poor quality can amount to elder abuse and the contravention of human rights (Carbone-Moane and Giacchetti-Vega, 2016; Rosenthal, Jehn and Galván, 2010). In high-income countries there is increased awareness of these issues

\footnotetext{
${ }^{1}$ http://www.taringa.net/posts/info/6916249/Cuatro-de-cada-diez-geriatricos-de-Buenos-Aires-sontruchos.html

${ }^{2}$ Recognising this knowledge gap, WHO recently launched series of reports on long-term care in low and middle-income countries (https://www.who.int/ageing/long-term-care/en/). This currently has a single study which is on sub-Saharan Africa.
} 
and the need for effective regulation and monitoring of service quality (Mor, 2014).

However, until now these issues have not been widely studied in Argentina or other LMICs. ${ }^{3}$

The paper applies a simple framework for analysing different aspects and criteria for LTC quality. Reducing quality in LTC to a simple, objective, operational definition is impossible (Day and Klein, 1987). Consequently, most quality assessments apply complex sets of indicators and standards, and there remains disagreement about which approaches are best suited to different contexts and aspects of LTC (Castle and Ferguson, 2010). Broadly, speaking indicators can be categorised as either inputs (service infrastructure, processes and resources) or outcomes (older people's quality of life, independence and capacity to do the things they value) (Shippee et al, 2015; Gascón y Redondo, 2014).

In high-income countries, increasing emphasis is being placed on outcome indicators (WHO, 2015). However, in LMICs the extent of formal service provision is often much more limited and fragmented, so quality assessment should begin with a review of inputs (CEPAL, 2009). Most broadly, this refers to the general availability of formal LTC services relative to demand, which in turn is a function of the number of people with care needs and the capacity of informal provision to meet these needs adequately. A second aspect of inputs is the LTC service mix. In high-income countries there has been a shift from an "all or nothing" choice between institutions and unsupported home care to a wider array of services, with a focus on ageing in place, person-centred care and case (or care) managers. Mixed service provision also includes integration between LTC and health services: a goal most highincome countries are a long way from achieving (WHO, 2015).

\footnotetext{
${ }^{3}$ In China, for example, the only published study on the quality of formal LTC, is a limited survey of 10 nursing homes in Chengdu (Hao et al, 2012).
} 
Evaluating the quality of LTC services is challenging for all countries. Quality assurance can involve diverse sets of actors, but it is generally agreed that state agencies should have an overarching "stewardship" responsibility (WHO, 2015). State roles include setting standards and ongoing oversight, through the licensing and certification of service providers (Mor, 2014). As part of this, the certification of LTC providers can link assessed quality to permission to operate and eligibility for funding. This requires regular audits of facilities, as well as comprehensive assessments of residents at admission and thereafter. Most highincome countries publish some of this information for service users to enhance transparency and support consumer decision-making. Over time, quality monitoring and accreditation has extended from a narrow focus on "hard indicators" such as building standards and safety, to take into account the quality of care-giving itself and the psychosocial wellbeing of residents and staff (Phillips, Hawes and Fries, 1993).

Even in high-income countries, there is an evident tension between these ideal roles and the "realpolitik" of LTC regulation. One dilemma is the need to maintain standards without undermining profitability for private providers, which might hence reduce supply (Mor, 2014). There are particular challenges in managing quality in home-based care, as this is, by definition, provided in private, domiciliary settings and often involves coordination between multiple agencies (Hirdes, et al, 2004).

In LMICs the capacity of state agencies to manage and regulate non-state actors, including private for profit organisations, is often limited (Zurbriggen, 2014). For example, state agencies often struggle to regulate private health care providers (Cárdenas et al, 2017). In this instance, there may be a need for civil society organisations to play a larger supporting role than in high-income countries. Limited state capacity also places a burden on service 
users to make and act upon their own quality evaluations. Ideally, this requires a degree of "care literacy" supported by reliable, publicly available information. ${ }^{4}$

The ultimate indicators of service quality are, of course, the outcomes for care dependent older people and their families. Outcome data range from more basic indicators such as consumer satisfaction to more ambitious methods, requiring detailed audits. Outcome objectives are increasingly framed in terms of users' wellbeing and the capacity of LTC to maintain and promote older people's independence and quality of life (WHO, 2015, WEDO, 2014). A separate focus on consumer rights stresses that older people and their families should be able to exercise a free and informed choice of services and should have continued access to suitable information on service quality (Wilberforce, et al, 2011). Systematic data comparing the effects of LTC systems on these outcomes are not available for OECD countries, and even less so for LMICs.

The few studies of LTC service quality in LMICs reveal widespread quality shortcomings and limited state regulation (Gutiérrez-Robledo et al, 1996; Giacomin and Camargos Couto, 2010; Lloyd-Sherlock, 2018; Cheung Wong and Leung 2012). For example, a review of care homes in Brazil found that around 40 per cent of residents had pressure ulcers: considerably higher than acceptable standards in high-income countries (Souza and Santos, 2007). Increasingly, local media are reporting these issues. ${ }^{5}$ Somewhat more information is

\footnotetext{
${ }^{4}$ This concept is comparable to health literacy (Findlay, 2015). It includes a basic understanding of conditions affecting older people, how to treat them, where to obtain appropriate support and how to evaluate service quality.

${ }^{5}$ For example of media reporting, see http://www.eltiempo.com/bogota/hogares-geriatricos-un-negociofuera-de-control/16341055 (Colombia), http://elvocero.com/investigan-muertes-en-hogares-de-ancianosfatulos/(Mexico); http://g1.globo.com/sp/campinas-regiao/noticia/2015/12/policia-militar-de-americanaencontra-duas-casas-de-repouso-clandestinas.html (Brazil).
} 
available about LTC quality in Argentina. In 2004/5 a survey was conducted of 101 private care homes in the city of Buenos Aires (Redondo and Lloyd-Sherlock, 2010). The study included interviews with care home managers, a questionnaire administered to 300 residents (excluding those with cognitive impairments) and more detailed interviews with an additional 10 residents. The study did not include a full quality audit, but provided numerous indications that services were often of a poor standard. In most care homes residents had little if any control over daily routines, and a high proportion reported low mood and that their quality of life had deteriorated significantly following admission.

The survey was restricted to LTC facilities included on official registers, and more than half of those homes approached refused to participate. Media reports indicate that many care homes operate on a clandestine basis and go unrecorded on official registers. Reliable data on the number of these unregistered care homes are not available: in 2010 it was claimed that at least 600 such homes existed in the city of Buenos Aires alone. Consequently, there is likely to be a heavy positive bias in the $2004 / 5$ survey.

In 2013/14 Argentina's Ministry of Social Development published the country's first national survey of care homes (Roqué et al, 2016). The survey covered 1,803 facilities: half the total identified in the 2010 Census. As such, the Ministry claimed that the sample was nationally representative. Nevertheless, the survey authors admit that its findings are also likely to have a positive bias, since the participation of care homes in the survey was entirely voluntary. Data were mainly derived from pre-arranged visits and interviews with care 
home directors, rather than from unannounced visits or from interviews with other staff, residents or residents' families.

\section{TABLE 1 ABOUT HERE}

Table 1 presents selected findings from the 2013/14 survey. It indicates that many care homes were falling well short of acceptable quality standards, in terms of both facilities and the treatment of residents. Few had individual bedrooms: rooms for three people or more were more common than single ones. In 17 per cent of homes some bedrooms lacked windows, 25 per cent had no private spaces for residents to meet with visitors and 33 per cent no specific space for recreation. A further 25 per cent were evaluated as insufficiently heated and 61 per cent as having problematic noise levels. Residents had few freedoms and powers: in nearly half the homes, residents were not permitted to personalise their rooms. Residents' rights to go outside the care home were often curtailed and 13 per cent of homes permitted no variation in (and hence resident influence over) daily routines. These findings are a reminder of and serve to demonstrate Goffman's concept of units acting as a 'total institution' but seen here, operating even now, in the $21^{\text {st }}$ century (Goffman, 1968). Overall, the survey observed that care homes tended to make more efforts to meet building and safety standards than to focus on the quality of life and related well-being of residents.

The Ministry of Social Development survey offers more comprehensive review of care homes than is publicly available for other LMICs. That said it still suffers from likely positive bias and a number of limitations. It mainly focusses on input rather than outcome quality indicators. The survey did not cover services provided in domestic settings, such as paid home carers. Paid domiciliary care for older people is becoming increasingly widespread in 
LMICs, but quality audits of such care are largely absent and there are indications that standards can be variable (Lloyd-Sherlock et al, 2017a; Lloyd-Sherlock et al, 2017b).

\section{Study design and methods}

Our study provides a detailed assessment of the quality of LTC facilities in a single city in Argentina. Such information is rarely available for LMICs, reflecting numerous barriers to systematic research. Government responsibility for LTC in LMICs is usually situated the municipal level and often shared across different agencies: health, social welfare and social insurance. For example, the Argentine Ministry of Social Development survey reviewed existing LTC legislation and found that most is enacted at local government level, with considerable variation in terms of both the laws and the agencies required to enforce them. As well as impeding coordinated state action, this decentralised approach hinders researchers' access to data (Lloyd-Sherlock, 2016). Services and providers are highly diverse, and many operate illegally, without state authorisation. State agencies often lack information about services, and illegal providers are understandably reluctant to participate in surveys.

Since orthodox survey methods are likely to be biased and unrepresentative, we developed a customised research design, focussing on a single city: La Plata, 35 miles south of Buenos Aires, Argentina. This selection was in part opportunistic, reflecting established networks with local stakeholders, but also reflected the benefit of studying a delineated urban setting in depth. La Plata is a medium-sized city of 650,000 people $(70,000$ aged 60 or more) and is relatively prosperous by national standards. 
Our study applied and combined a range of different qualitative methods, with data collection conducted sequentially (Figure 1). We began by reviewing available data and grey literature relating to LTC in La Plata. This stage of data collection occurred alongside interviews with 9 local key informants, including hospital staff working in geriatric care, local government officials responsible for care services, representatives of local NGOs with interests in LTC, and the director of a private care home (not included in the subsequent survey). They spoke in personal capacities and their contributions were fully anonymised. There were no refusals. The interviews assessed personal knowledge of LTC services in La Plata and perceptions of service quality.

We then selected two "pensioner clubs" from around 100 such clubs in La Plata. ${ }^{6}$ Selection was opportunistic (through local contacts), and included a club in a relatively poor neighbourhood and another in a lower-middle district. We contacted the presidents and organising committees of each club and gave them a description of the project. Further information was provided in each club's weekly general meeting, during which members were invited to participate in focus group discussions, which took place in private rooms in the clubs. The focus group guide assessed participants' general knowledge and perceptions of different local care homes and other LTC services. Questions referred to patterns of LTC service use, experiences of these services, reasons for using services, sources of information about services and perceptions of service quality.

The subsequent and most innovative aspect of the study design was a clandestine audit conducted by pensioners living in La Plata. We recruited six pensioners from an established

\footnotetext{
${ }^{6}$ These clubs are community organisations run by pensioners and mainly offer leisure and social activities. They do not have a particular focus providing services for people with functional impairment and therefore are not part of the local LTC infrastructure in a way that community day centres in other countries are.
} 
local "Elder Activist Network" which had previously studied local amenities for older people, as part of a World Health Organisation initiative (IADB, 2015). These "pensionerresearchers" were trained to undertake observational research on care homes in their own neighbourhoods. Preparation included training sessions led by members of the project team, of whom one was a locally-based qualified social worker. Initial sessions provided general information about the study, and allowed pensioner-researchers to work alongside the authors to develop a structured questionnaire and agree a suitable approach. A final session included a more detailed review of the guide, mock interviews, discussion about how to establish contact with care homes and the selection of homes to be visited.

The agreed approach, partly developed in advance of the training sessions and modified during them, first involved pensioner-researchers telephoning local care homes with an enquiry about a fictitious family member in need of institutional care. This was based on the following scenario:

I am looking for somewhere to look after my sister. She has some problems with her behaviour and can't manage things for herself at home.

The fictional sister's "behavioural problems" were left intentionally vague in the phone call, and may or may not have entailed dementia. Having obtained some information, the pensioner researchers made personal visits to the care homes, to ask a representative of the home further questions and conduct observational research. These questions were led by a structured questionnaire (see Appendix 1 for translation), which refers to a range of issues, including general features of the care home (size, location, type of services provided and so forth), admissions procedures and requirements, and perceived quality based on interview and observations during the visit. Interviewees were selected opportunistically, in terms of 
which member of care home staff hosted the pensioner-researchers during their visit. In some cases they were owners, in others they were employees of varying levels of seniority. The pensioner-researchers conducted 30 interviews in separate homes, selected from a list developed in earlier in the study. These account for roughly half of all care homes in the city. Efforts were made to cover the full range of prices and conditions, and care homes with previous links to the pensioner-researchers were excluded. Only one care home refused to participate and this was on the grounds that it had no available places. During fieldwork, the research team remained in frequent contact to offer support and advice.

Use of the surrogate patient approach in research presents important ethical challenges, as the researchers misrepresented their true identities and did not obtain informed consent from the research subjects (care home directors and employees). However, it is accepted that this method is ethical where (i) it does not expose research subjects to harm; (ii) the waiver of consent is necessary to obtain scientifically valid data; (iii) the potential social value of the knowledge to be gained from the research is substantial and (iv) participants will be given information subsequent to the study (Rhodes and Miller, 2012; Pager, 2007). This study met all these criteria and full ethical approval was obtained from the relevant committee of the University of East Anglia (that was relevant to the main author). The study also ensured that the research design did not contravene Argentinian law.

The final component of the study design consisted of repeat interviews and a focus group with key informants, to share and discuss initial anonymised study findings. These meetings were informal and covered the full range of topics included in the study. Lastly, an open, public dissemination meeting, publicised by local media, was held in a prominent venue in central La Plata. 
This mixed study design generated a complex set of different types of data, aiming to provide a rich, contextualised case-study and to reduce response bias. It does, however, create challenges for interpretation and reconciliation. Our main analytical strategy was triangulation across the different data and we sought out data that contradicted or did not fit with more general assertions. The risk of either positive or negative bias was not eliminated. For example, in the follow-up meeting pensioner-researchers commented: "I had a sense that they are used to this sort of visit, that they are forewarned and cover up a lot of things" and "There was some reticence in responding to my questions". Several of the narratives from the focus groups conducted at pensioner clubs included a strong element of self-justification when referring to personal experiences of placing relatives in care homes. Conversely, negative bias may result from the study team's own prior perceptions of care home quality in the city of Buenos Aires.

The analytical strategy was based on a framework approach, which facilitates comparison across different forms of qualitative data and different types of respondent (Smith and Firth, 2011). We then conducted thematic analysis of the full transcripts of the qualitative data (in the original Spanish) using manual coding, guided by our research interests and insights from the wider literature. Preliminary interpretations of the data were shared with key informants during the second wave of interviews and the follow-up focus group, in order to both assess their validity and further develop the enquiry. This phase of the study included more focussed discussion of prominent themes. Analysis was also shared at the public dissemination meeting, further supporting validation. Additionally, a research summary in Spanish was shared with Latin American gerontologists, who were asked to compare its findings to other locations they were familiar with. 


\section{Formal LTC service availability in La Plata}

Over the past decade, there has been a rapid extension and, to a lesser extent, diversification of LTC services in many parts of Latin America (Huenchuan and Rodríguez Velázquez, 2015; Gascón and Redondo, 2014; Camarano et al, 2010). La Plata is no exception to this trend with residential care facilities currently numbering around 60, mainly run on a private for-profit basis. In 2016 it was estimated by local key informant health and social care professionals that the city contained around 60 care homes for older people, of which all but two were run by private organisations. These ranged from informal "boarding house" care homes with untrained staff, to luxury nursing homes, which claimed to have a full range of therapeutic services. In 2016 prices ranged from around US\$460 a month for the former to over US\$2,600 for the most expensive provision (excluding the cost of incontinence pads and other medical supplies). La Plata also contained eight day care centres, again run mostly on a private for-profit basis and including three specialising in provision for older people with dementia. Support for home care has become increasingly available, including several agencies offering paid home carers, the provision of cash payments to cover home care costs, a "hospital at home" programme for highly dependent older people and a private helpline offering information and advice to family carers.

The range of agencies and actors involved in La Plata's LTC is equally diverse. The provincial and the municipal ministries of health are both authorised to inspect and grant licenses for care homes to operate. They also have responsibility for accreditation of paid home care nurses. Separately from these ministries, social health insurance funds offer members a range of LTC services, and inspect and license approved providers. As in other parts of Latin 
America, religious organisations have traditionally provided residential LTC for poorer social groups, sometimes with local government funding. In the case of La Plata, this provision was limited and had been scaled back in recent years. By contrast, private for-profit providers are playing an increasingly prominent role, particularly in residential care. Various private sector companies specialise in providing trained geriatric nurses and carers for home care and in operating more intensive hospital at home services.

Although La Plata contains an increasingly complex constellation of LTC services and providers, there are important gaps in service coverage. Publically-funded geriatric health and care services have been reduced over time. The Ministry of Health's mental health services (which traditionally treated people with dementia) have been curtailed by a policy of returning inpatients to the community. As a result, the supply of specialist LTC services remains limited relative to demand. The number of care homes certified and funded by social insurance agencies remains small and they typically have waiting lists of 50 to 100 people. Key informants observed that in many cases applicants die before admission. State and social insurance support for domiciliary care is similarly limited. The main social insurance fund for pensioners offers cash support to cover the cost of home care. However, payments are usually capped at around $£ 40$ a month, representing a fraction of actual costs in most cases. In theory, more generous payments are available for people with complex care needs, but the number of these paid out is very small. For example, the main provincial social insurance fund paid only 200 complex care benefits for a membership of 25,000 people aged 65 and over.

Though the range of provision is increasingly broad, it does not include some services found in high-income countries, such as training and respite for unpaid family carers or sheltered 
housing. In particular, provision for complex care needs remains limited and many care services exclude older people with challenging conditions such as dementia. Three privatelyrun dementia day centres have been established in recent years, but have limited capacity and are prohibitively expensive for most of the population. A local health worker commented:

If they go to a health centre, they might get their blood pressure measured: but nothing else.

As well as gaps in LTC provision there were important limitations in the availability of mainstream health services for older people. Key informant hospital staff and social workers observed that neighbourhood clinics almost entirely focussed on conditions such as maternal and child health, and on acute care rather than chronic health conditions, adding that nurses had little if any training in geriatric conditions.

The main form of health care engagement with older people was through regular visits made by nurses to local pensioner clubs, which numbered around 100 across the city. These visits provided a range of useful services, including checking blood pressure and offering health promotion advice. However, no specific provision was made for dependent older people. Official informants estimated that only 17 per cent of older people regularly attended the clubs and rates of participation were much lower for older people who had more limited mobility or other forms of dependency. Outside the pensioner clubs, access to health services often required travel to central La Plata or even Buenos Aires city. Local key informants agreed that there was an acute shortage of hospital beds for older people in La Plata, generating long waiting lists and leading to transfers to other cities. 


\section{Perceptions of LTC service quality}

La Plata contains a large number of residential care homes, with a wide range of costs. As such, it might be expected that quality would also vary. There was consensus across all study participants that the quality of care offered by the cheaper care homes was usually very poor. According to a private care home manager:

You just take any type of house and then add on rooms at the back, without any proper planning or spaces.

A social worker added:

Most of these houses are very old and run down, miserable and dark. The people working there have no training and look after maybe 10 or 12 older people as best they can.

There was less agreement about more expensive care homes. Several wealthier older people emphasised the high quality of care provided by establishments, which had admitted their own family members. However, older people who had themselves worked in more expensive care homes, and the pensioner-researchers, expressed scepticism that high cost guaranteed better quality. A distinction was made between aspects of provision more readily discerned by family members and what went on "behind the scenes":

I've worked as a nurse in several homes. The way they treat the residents is awful... They're always full, so at three in morning they start to get the residents up, take them to the toilet and bathe them.... I used to hear people say "I'Il just give you a little pill so that you'll leave me in peace, OK? ... They used to know when relatives 
were due to visit... "We need to get grandma ready for when they get here", clean, tidy, in nice clothes, so the relative comes and hey presto happy grandma!

In the most expensive care home surveyed (costing over $£ 1000$ a month), rooms were welllit and clean and a qualified doctor was notionally in charge. The doctor, who was also the home owner, would usually conduct the initial admission interviews with family members. However, residents were usually cared for by a single unqualified worker, shared spaces were extremely cramped and the small garden was inaccessible for the residents. Similarly, certification from a social insurance agency did not guarantee good care; in part, because there was over-demand for places. One social insurance worker admitted:

There isn't even any interaction [with residents]. Many times I've seen that in the process of transferring someone from a wheelchair to a bed the carer doesn't ask "Would you like to get up now?" "Would you like something to eat or drink"... Nothing..... When you go inside it's very [tails off]. It really upset me at first. Care home routines and interaction between staff and residents rarely sought to enhance residents' autonomy or functional status, a further reminder of Goffman's description of 'total institutions' (Goffman, 1968). Several key informants observed that, in more reputable homes, staff tended to "look after" older people. One local government official observed:

What we have noticed is that when some people are admitted they may have problems going to the toilet, but can still manage to do it with some help. But then they are made to wear incontinence pads and lose the ability to go to the toilet. They put them in nappies straight away, just for convenience. They deal with residents in 
a standardised way: they bathe them at a set time, get them up at a set time, then put them to bed at a set time.

Similarly, in a highly-regarded care home run by a church organisation:

They care for and support older people in a very respectful way... There are lots of volunteers, lots of artistic activities. But, well... they don't have any interest in rehabilitation or psychiatric support.

A clandestine researcher reported:

When they opened the door for me to see the rehabilitation room, it was freezing. I could tell nobody had been in there for a long time.

More generally, there were indications that many care homes did not respect the dignity or human rights of residents. The clandestine survey found that almost no account was taken of older people's own wishes or informed consent in admissions decisions. ${ }^{7}$ None of the homes surveyed, even the most expensive, had individual bedrooms and doors were typically left permanently open, so staff could observe residents' behaviour, including when dressing. During visits, the clandestine researchers mentioned that their fictitious sister sometimes experienced falls and asked how this would be dealt with. Eight of the 30 homes were not prepared to give specific responses, and a further eight said they would use physical restraints. In some cases, they referred to the use of torn bed sheets as restraints. It was not possible to systematically assess how much care homes used psychotropic medication to sedate residents. However, the pensioner-researchers usually observed

\footnotetext{
${ }^{7}$ For a detailed discussion of admissions see Lloyd-Sherlock et al, 2018.
} 
limited activity, alertness and conversation among residents. Most visits were made at lunchtime, which was typically observed to be entirely silent. According to one researcher: During my visit, I didn't hear a sound. I didn't hear any voices.

Across all the different sources there was agreement that the quality of home-based LTC services was also often poor. According to focus group participants:

I was at the greengrocers and saw this person who was completely confused. I could see that she could hardly stand up. I took her arm and asked her: "Lia, what are you doing here? And she said "I've just come to run some errands". "What about the girl who looks after you?" And she says "Oh, she's back in the house drinking tea". "So what are you doing here?" "Because there are things I need to buy."

The first time they called me to their house, when I saw the old lady I nearly fainted. I was there to cut her hair, cut her finger and toenails... The old lady wouldn't let anyone touch her, not even the girl who was looking after her, who was meant to be a home care specialist... Oh, when I saw her feet I wanted to die! Between the toes which had not been cleaned properly for some time, there was a sort of brown shell. So with tweezers, cotton wool and cream I cleaned her feet. Then I called over to the carer and asked: "Who's supposed to be bathing this lady"?

My sister has problems with her legs. She is in a good economic position, but older women like her are afraid about what happens if you allow someone into your home. Someone who is there with you all day long and through the night... Some young girl who then brings her boyfriend along. 
A number of organisations provided home carers with varying levels of cost and qualification. Social insurance agencies played no role in either training or accrediting workers in care homes or those paid through home care benefits. Carer training was mainly left to the provincial Ministry of Social Development, which claimed to have trained over 1,200 carers between 1996 and 2016. According to one informant:

We've extended our training programme very quickly to meet the demand, so that we don't get to know the trainees as well as we used to. And we are now starting to get reports of theft... Our carers are stealing jewellery and other items. ${ }^{8}$

Another added that many trainees did not continue as carers for long, since:

Some people who go on those courses think they're going to be some kind of luxury nurse who will make house calls. Then they discover the great physical and psychological effort needed to clean an older person, toilet and wash them, and that it is an unpleasant job.

There was also broad consensus that the more intensive "hospital at home" services were both difficult to obtain and poorly coordinated. For example, one focus group participant discussed the case of her father who was highly care-dependent and in the final stages of Parkinson's disease. She was able to obtain some paid carer support from a social insurance fund, as well as other forms of assistance such as a wheelchair. However, much of this took several months to be provided, only arriving shortly before her father's death. The fund also provided an orthopaedic bed for her father, but the mattress did not arrive until after her

\footnotetext{
${ }^{8}$ There were unconfirmed reports that the national training programme had included large numbers of former convicts, who struggled to obtain paid employment through other means.
} 
father had died. She approached numerous care homes, but none were prepared to admit someone with such a high level of dependency.

Given the shortcomings of mainstream health services and the fragmentation of LTC provision, the prospects for effective integration were poor. This was apparent in a number of ways. First, family doctors and primary health clinic staff were not usually well-informed about local LTC services. Health workers' limited knowledge of LTC issues was reflected in the testimony of one focus group participant:

I lost my husband and a little while later I went for some tests. I live alone, look after myself and haven't had any problems till now.... When I first met the doctor he asked "How old are you?" "80". "And you are still living on your own?" "Yes".... "But at that age you are not capable of living on your own!"... I went home and started to get a bit depressed... The doctor had said that, but he didn't know anything about me.

One frequent result of the limited integration between the health and LTC systems, reported by many respondents, was unnecessary blocking of hospital beds. One of the few hospital-based geriatricians in the city explained the difficulty of discharging older patients without home support:

We have to find out where they live and where their nearest health centre is... We get in touch with the health centre to see if they know the patient... Then someone may tell us about a neighbour and we try to get them to agree to look after the patient or at least keep an eye on them. We had a gentleman who had suffered a heart attack... he was in here for a long time. His only relative was a brother in Almirante Brown [20 miles away]... When he got better we had to send him back to 
the boarding house that he'd come from. A boarding house!... We sent the brother to a government care home in Almirante Brown to see if they could take him. We did all the paperwork, sent all the documentation, so that he would get on the waiting list... But we didn't succeed.

Due to concerns about bed-blocking, the sole public hospital offering rehabilitation to older people only admitted patients who could demonstrate that they had relatives to care for them upon discharge. Additionally, this facility did not usually admit people with dementia, since its services did not include any form of psychiatric rehabilitation. The lack of specialist services for people with dementia led to extended stays in general hospital wards, as reported by one focus group participant:

My mother had senile dementia... The time came when she didn't recognise me anymore... She had serious heart problems, so they admitted her to Mosconi de Berisso hospital. She was in there for three months... Then the doctor discharged her... In the end she was readmitted to San Juan de Dios Hospital. She had an irregular heartbeat and, well, she died there.

\section{Regulating LTC service quality}

In Argentina there is no nationwide set of LTC standards or protocols and registers of certified care homes are very incomplete. Responsibility for regulating and overseeing LTC is almost entirely devolved to provincial and municipal governments. Consequently, the approach taken to LTC regulation varies between provinces. Buenos Aires Province is one of the wealthiest and the capacity of poorer provinces to regulate LTC is likely to be more 
limited. Legislation in the Province of Buenos Aires stipulates that care homes should be subjected to periodic visits from multi-disciplinary teams of at least eight professionals and sets out a long list of regulations and standards. According to one government social worker:

I feel that there is so much regulation now. So many things the care homes have to comply with that only a few of them can realistically comply.

As in high-income countries, La Plata has a system of certifying LTC facilities that receive state accreditation and social insurance funding. Almost all care homes prominently display certificates of accreditation either from social insurance funds, the provincial ministry of health $(\mathrm{PMH})$ or its municipal counterpart. The precise roles these agencies played in relation to each other was not always clear. One informant noted that most preferred to be certified by the municipal ministry, as its standards were less stringent. For example, it did not stipulate a maximum number of older people to a bedroom, while the provincial ministry set this at two.

Provincial legislation does not specify how often LTC facilities should be inspected. However, in 2012 a representative of the provincial ministry claimed it had audited around 600 homes across the province in the previous six months, representing roughly 20 per cent of those it had identified in the province. ${ }^{9}$ The ministry also claimed to have trained 85 care home inspectors in 25 municipalities during the previous year. However, several key informants noted that both ministries focussed almost exclusively on physical aspects of care homes, such as fire exits and smoke alarms, but not on issues such as staffing, the use of restraints

\footnotetext{
${ }^{9}$ http://www.agencianova.com/nota.asp? $\mathrm{n}=2012$ 2 $14 \&$ id =30068\&id tiponota=11
} 
and sedatives or respect of older people's rights. This is in contrast to developments over several decades in high-income countries, such as the US and countries within Europe. These include the steady evolution of care standards to include psychosocial aspects of care and accord these parity with more physical aspects such as hygiene and safety. Examples of this can be seen in the Federal Nursing Home Reform Act 1987 in the US and developments in the UK following the Registered Homes Act 1984, which lead to reports such as Homes are for Living In (DoH/SSI, 1989) and the My Home Life initiative which commenced in 2003 (Owen and NCHRDF, 2006), with an emphasis on more psychosocial aspects of care provision. The drive towards changes in the culture of care within institutions is now occurring in many countries across the world and is ongoing.

Both the provincial and municipal governments also had divisions specifically concerned with older people's welfare (Secretarias de la Tercera Edad), located in their respective Ministries of Social Development, not the Ministries of Health. These divisions did not certify care homes, but had general roles in overseeing quality and responding to complaints. However, resources were extremely limited and there were evident problems of governance. The change of provincial government in early 2016 had led to a virtual suspension of these services. Seven months after taking up her post, the new head of the provincial division observed that her travel budget was so limited that she could only visit nearby care homes. Similarly, at the time of fieldwork for this study, the municipal social development office was beset by a related political scandal and was largely unable to function. ${ }^{10}$

\footnotetext{
${ }^{10}$ For related media reports, see http://www.eldia.com/la-ciudad/tironeos-en-el-consejo-de-la-tercera-edad148426 and http://www.diariocontexto.com.ar/2016/06/17/el-socio-politico-de-garro-tenia-una-agencia-deviajes-en-su-despacho/
} 
Although the provincial social insurance fund had a register of 23 care homes, its capacity to audit them was also minimal. Due to concerns about staff absences, all staff were prohibited from working outside the city centre office. This reduced capacity to regulate care homes: auditors' only option was to interview care home managers by 'phone. One key informant observed that several care homes providing sub-standard services were in fact owned by former directors of this social insurance fund.

By contrast, staff of the national social insurance fund for pensioners were still permitted to leave their offices to visit care homes which had been subject to complaints. These visits were portrayed by one informant as professional and robust:

We really work as a team, with different professionals -a social worker, a doctor, a nurse, a psychiatrist if necessary, an engineer and a nutritionist -food is an essential concern for us. We show up at any time of day, sometimes at night... we make a record of everything, in case we go on to make an official complaint... It's a surprise for them when we show up and we don't even share our plans with our colleagues here. Only people inside our team know. And showing up like that, obviously you find some unpleasant things sometimes. Then we act quickly, automatically shutting the home down. The other day we made a visit and found a lot of people with scabies who were not being treated. We also found the kitchen was in a terrible state. We went to another home because there had been a lot of complaints and we found the food was so awful we had to shut it down there and then.

Once they temporarily shut down a care home: 
We make a report... We stop paying the home. This is something new. It means that they won't have access to our funds until they resolve the situation.... You give them a specific time period to sort themselves out, usually 48 hours. If the situation hasn't improved in those 48 hours, then you have to start thinking about evacuating the residents... But we've never actually had to do that.

The failure to go beyond a two-day closure suggests that the sanctions applied by the social insurance fund were quite limited and weakly enforced. The emphasis placed on not informing colleagues within the same organisation about planned visits, is a further indication of challenges of governance facing the regulatory system as a whole. In the follow-up meeting with key informants, a social worker referred to a care home inspection that had taken place during the winter, which had found that the heating had been turned off to save money. Other than informally sharing her concern with the care home manager, no formal actions were taken.

Regulation of domiciliary care differed from care homes. Care workers paid by the national pensioners' social insurance fund's cash benefits for dependent members were not required to submit proof of their qualifications or experience. The logic was that older people could exercise their own choices and judgements as "informed consumers". By contrast, regulation of care workers providing more specialised and intensive hospital at home services appeared complex and rigorous. Obtaining support for this service required the applicant to find a nurse whose qualifications met official standards, obtain certification of the older person's dependency from a doctor and submit information about family circumstances. The nurse was then required to submit a detailed care plan for vetting. An official from the social insurance agency admitted that people with dementia were 
considerably less likely to get support, since nurses' qualifications and proposed care plans rarely met their exacting standards for dementia care. Applications were reviewed in the social insurance office, without home visits. Once contracts were awarded, regulation became minimal. The same key informant described their response to complaints:

We just pass them onto our legal team. None of the team has a background in that issue. They just have experience in chasing up payments... That's what they are generally interested in and responsive to... A month ago we were finally able to suspend one of our carers, but that had taken us about six months.

Not surprisingly, several informants noted widespread abuse of the hospital at home scheme, which has also been reported in the media. ${ }^{11}$ The contrast between the demanding application process and the laissez-faire approach thereafter indicates that the main objective was to limit the number of hospital at home care contracts (which were often expensive) rather than to ensure quality. In May 2016, the new director of the pensioners' insurance fund admitted that it was making hospital at home payments for hundreds of people who were no longer alive. ${ }^{12}$

The capacity of state agencies to effectively manage LTC services was curtailed by their limited resources and powers, as well as by poor governance. The complexity of the LTC system, in terms of different services, providers, funders and contracts created particular opportunities for corrupt practice.

\footnotetext{
${ }^{11}$ In 2010 a newspaper exposé revealed corrupt contracting between insurance funds and private firms providing hospital at home services (http://www.latecla.info/4/nota.php?nota_id=43320 see also http://www.lanacion.com.ar/1860028-denuncian-que-ioma-paga-por-unos-9000-servicios-fantasma).

12 https://estodolocontrario.wordpress.com/2016/05/04/en-el-pami-revendian-medicamentos-y-seencontraron-sillas-de-ruedas-nuevas-abandonadas/.
} 
More generally, there was little evidence of integration or coordination between the many actors and components of the LTC system. When stakeholders were asked about meeting, let alone working with, their counterparts in other organisations, all responded that this had not been actively considered. This lack of coordination was striking given the small size of La Plata, the close proximity of offices, and strong informal networks (for example, several informants had been trained in the same department of the local university).

Beyond the state, there were no organisations with particular interests in LTC. La Plata contains a number of NGOs and government agencies concerned with human rights. Of these, the Defensor del Pueblo de la Provincia de Buenos Aires had some focus on LTC, but only in government-run facilities. This organisation had a very broad remit, including domestic violence against women, policing standards, environmental protection and consumer rights, effectively limiting the attention it could give to LTC.

There may be scope for service users to hold providers to account, if adequate information could be available in a suitable form. This was clearly not the case in La Plata. There was agreement among informants that family doctors and other health workers were not a reliable source of information. There was some mistrust of doctors, with newspaper accounts that they would only provide certificates for home care if they received payments from the private firms that would then provide the service. ${ }^{13}$ The primary source of information about LTC services and their quality was by word of mouth. One additional source of information was occasional media exposés of care home scandals and elder abuse, which added to users' uncertainty and general mistrust of the system.

\footnotetext{
${ }^{13}$ http://www.lanacion.com.ar/1860028-denuncian-que-ioma-paga-por-unos-9000-servicios-fantasma.
} 


\section{Conclusion}

This paper applies a simple conceptual framework and a novel research design to assess the quality of formal LTC services in the city of La Plata. Since LTC provision in most countries is delegated to local government and since reliable data are often unavailable, this approach may be suited to studies in other local settings. This would allow for more comprehensive and comparative perspectives on a rapidly emerging set of phenomena.

The paper shows that general service availability has increased, with the emergence of a complex system of provision, involving a wide range of state and non-state actors. At the same time, systems of regulation and quality control are essentially absent. The paper reveals shortcomings in all aspects of formal LTC in La Plata, including both residential and domiciliary services. The system as a whole is fragmented, poorly articulated and lacks integration with mainstream health services. There are evident gaps in provision, especially for older people with complex care needs, and the quality of services across both sectors is frequently very poor. Residential services focussed on quality standards related to building and safety standards, reflecting the main concerns of regulatory agencies. By contrast, issues such as the inappropriate use of restraints and psychotropic drugs were not identified by key informants or older people in the focus groups. This is likely to encourage a culture of residential care that emphasises control and regimentation, in line with Goffman's (1968) concept of the 'total institution' -an approach which has been discredited as unacceptable and tantamount to abusive in high-income countries (Weinstein, 1994; Koren, 2010).

The capacity of state agencies and social insurance schemes to effectively regulate La Plata's formal LTC providers is negligible and prospects for immediate improvement are not good. 
These agencies have few resources and weak institutional capacities, and display little appetite for working together to develop more robust systems of regulation. As such, whilst the notion of "state stewardship" of LTC, as proposed by WHO, remains appealing in theory, its application in practice may appear sometimes be a case of wishful thinking (WHO, 2015). In the absence of effective state action, a more effective approach may be to work more directly with older people and their families. Interventions seeking to enhance care literacy and access to information about LTC may enhance the capacity of older people and their families to hold both providers and responsible state agencies to account. This might also serve to enhance expectations of what LTC provision should be. More generally, there is a clear need to raise the public profile of this issue, with an informed and inclusive national dialogue about the challenges of meeting LTC needs and the evident failures of the current system.

The paper has little to say, directly, about the effects of formal LTC services on older people's wellbeing. The research design did not permit the systematic collection of data on these effects, although some of the qualitative evidence presented in this paper alludes to them. It is highly likely that the observed poor service quality and lack of regulation has led to poor outcomes for older people and their families.

A Spanish language draft of this paper was shared with a network of gerontologists in Argentina, Mexico, Chile, Colombia, Brazil and Uruguay. All commented that the findings broadly conformed to the situation in their own cities and countries. In the follow-up key informant meeting, there was a strong consensus that the quality and availability of LTC services elsewhere in the Province of Buenos Aires were considerably worse than in La 
Plata. ${ }^{14}$ If this is true, hundreds of thousands of vulnerable older people with care needs are exposed to poor quality care and in some cases this represents an infringement of their fundamental human rights.

14 There are some media reports that support this claim. In February 2018, it was reported that of 30 care homes operating in the city of Tres Arroyos (population 57,000), 27 were completely unregulated http://lavozdelpueblo.com.ar/noticia/70298-

Tres\%20geri\%C3\%A1tricos\%20habilitados\%20y\%20m\%C3\%A1s\%20de\%20veinte\%20\%22clandestinos\%22\%20 


\section{References}

Camarano, A., Kanos, S., Leitão e Mello, J. and Fernandes Carvalho, D. (2010) “As instituições de longa permanência para idosos: abrigo ou retiro?" in A.Camarano, ed. Cuidados de longa duração para a população idosa: um novo risco a ser assumido? IPEA, Rio de Janeiro.

Carbone-Moane, C. and Giacchetti-Vega, M. (2016) Malnutrición en adultos mayores institucionalizados en un asilo de Lima, Perú Revista Peruana de Medicina Experimental y Salud Pública 33, 175-6.

Cárdenas, W., Pereira, A. and Machado, C. (2017) Trajetória das relações público-privadas no sistema de saúde da Colômbia de 1991 a 2015. Cadernos de Saúde Pública 33, Supplement 2:e00114016.

Castle, N. and Ferguson, J. (2010) What is nursing home quality and how is it measured? The Gerontologist 50, 426-42.

Cheung Wong, Y. and Leung, J. (2012) 'Long-term care in China: Issues and prospects' Journal of Gerontological Social Work, 55, 570-86.

Comisión Económica para América Latina y el Caribe (CEPAL) (2009) Envejecimiento y sistemas de cuidados: ¿̇oportunidad o crisis? CEPAL, Santiago de Chile http://repositorio.cepal.org/bitstream/handle/11362/3859/1/S2009000_es.pdf

Day, P. and Klein, R. (1987) The regulation of nursing homes: a comparative perspective. The Milbank Quarterly 65, 303-47.

DOH/SSI: Department of Health/ Social Services Inspectorate (1989) Homes Are For Living I $n_{\mathbf{L}}$ London: HMSO. 
European Partnership for the Wellbeing and Dignity of Older people (WEDO) (2014)

European Quality Framework for long-term care services. Principles and guidelines for the wellbeing and dignity of older people in need of care and assistance

\section{http://wedo.tttp.eu/system/files/24171 WeDo brochure A4 48p EN WEB.pdf}

Findlay, A. (2015) Low health literacy and older adults: meanings, problems, and recommendations for social work. Social Work in Health Care 54, 65-81.

Gascón, S. and Redondo, N. (2014) Calidad de los servicios de largo plazo para personas adultas mayores con dependencia. CEPAL, Santiago de Chile http://www.cepal.org/es/publicaciones/36948-calidad-de-los-servicios-de-largo-plazo-parapersonas-adultas-mayores-con

Giacomin, K. and Camargos Couto, E. (2010) “A fiscalização das ILPIS: o papel dos conselhos, do ministério público e da vigilancia sanitaria" in A.Camarano, ed. Cuidados de longa duração para a população idosa: um novo risco a ser assumido? IPEA, Rio de Janeiro. Goffman, E. (1968) Asylums, Harmondsworth (London): Penguin Books Gutiérrez-Robledo L., Reyes-Ortega G., Rocabado-Quevedo F., et al. (1996) Evaluacíon de instituciones de cuidados prolongados para ancianos en el Distrito Federal. Una visión crítica. Salud Pública de México 38, 487-500.

Hao, Q., Wu, S., Ying, L., Luo, L., Dong, D. and Dong, B. (2012) Current dilemmas of nursing homes in Chengdu: a cross-sectional survey. Journal of the American Medical Directors' Association 13, 406.e9-12. 
Hirdes, J., Fries, B., Morris, J., Ikegami, N., Zimmerman, D., Dalby, D., Aliaga, P., Hammer, S. and Jones, R. (2004) Home care quality indicators (HCQIs) based on the MDS-HC. The Gerontologist 44, 665-79.

Huenchuan, S. and Rodríguez Velázquez, P. (2015) Necesidades de cuidado de las personas mayores en la Ciudad de México: diagnóstico y lineamientos de política. CEPAL, Santiago de Chile http://www.cepal.org/es/publicaciones/38879-necesidades-de-cuidado-de-laspersonas-mayores-en-la-ciudad-de-mexico

Inter-American Development Bank (IADB) (2015) Age-friendly cities: How urban planning can keep older people active. http://blogs.iadb.org/ciudadessostenibles/2015/11/23/agefriendly-cities-2/ [accessed 20.2.17].

Koren, M. (2010) Person-centered care for nursing home residents: the culture-change movement. Health Affairs 29:312-317.

Lloyd-Sherlock, P. (2016) Barriers to linking research and policy: the case of long-term care in low and middle-income countries. Population Horizons 12, 62-7.

Lloyd-Sherlock, P., Mayston, R., Acosta, A. et al. (2017a) Allocating family responsibilities for dependent older people in Mexico and Peru. Journal of Development Studies. 54, 682-701.

Lloyd-Sherlock, P., Sasat, S., Morales, F. and Pot, A-M. (2017b) Long-term-care policy in Thailand and Costa Rica and the role of volunteers: Key success factors for development and implementation. Bulletin of the World Health Organisation 95, 774-778.

Lloyd-Sherlock, P., Penhale, B. and Redondo, N. (2018) The admission of older people into residential care homes in Argentina: Coercion and human rights abuse. The Gerontologist doi: 10.1093/geront/gny014. [Epub ahead of print] 
P.Lloyd-Sherlock (2018) Long term care for older people in South Africa: the enduring legacies of apartheid and HIV/AIDS. Journal of Social Policy 48, 147-167.

Mor, V. (2014) "A framework for understanding regulation of long-term care quality" in V.Mor, T.Leone and A. Maresso (eds) Regulating long-term care quality: an international comparison. Cambridge University Press, Cambridge.

Owen, T. and NCHRDF (2006) (eds) My Home Life: Quality of Life in Care Homes, London: Help the Aged, National Care Forum (NCF) and National Care Home Research and Development Forum (NCHRDF).

Pager, D. (2007) The use of field experiments for studies of employment discrimination: contributions, critiques and directions for the future. Annals of the American Academy of Political and Social Sciences, 609: 104-133.

Phillips, C., Hawes, C. and Fries, B. (1993) Reducing the use of physical restraints in nursing homes: will it increase costs? American Journal of Public Health 83, 342-8.

Redondo, N. and Lloyd-Sherlock, P. (2010) Institutional care for older people in developing countries: Repressing rights or promoting autonomy? The case of Buenos Aires, Argentina. Journal of Population Ageing 2, 41-56.

Rhodes, K. and Miller, F. (2012) Simulated Patient Studies: An Ethical Analysis. The Millbank Quarterly 90, 706-24.

Roqué, M., Fassio, A., Arias, C. and Croas, P. (2016). Residencias de larga estadía para adultos mayores en Argentina. Relevamiento y evaluación. Ministerio de Desarrollo Social. Buenos Aires. http://www.algec.org/biblioteca/RESIDENCIAS LARGA-ESTADIA.pdf 
Rosenthal, E., Jehn, E. and Galván, S. (2010) Abandoned \& Disappeared: Mexico's

Segregation and Abuse of Children and Adults with Disabilities. Disability Rights

International and Comisión Méxicana de Defensa y Promoción de los Derechos Humanos,

New York. http://www.disabilityrightsintl.org/wordpress/wp-content/uploads/Mex-Report-

\section{English-Nov30-finalpdf.pdf}

Shippee, T., Henning-Smith, C., Kane, R. and Lewis, T. (2015) Resident- and Facility-Level Predictors of Quality of Life in Long-Term Care. The Gerontologist 55(4):643-55.

Smith, J. and Firth, J. (2011) Qualitative data analysis: the framework approach. Nurse Res. $18,52-62$.

Souza, S. and Santos, S. (2007) Factores de riesgo para el desarrollo de úlceras por presión en ancianos atendidos en asilo [Risk factors for pressure ulcer development in institutionalized elderly]. Revista Latinoamericana de Enfermagem 15, 958-64.

Weinstein, R. (1994) Goffman's Asylums and the total institution model of mental hospitals. Psychiatry 57, 348-67.

Wilberforce, M. et al (2011) Implementing Consumer Choice in Long-term Care: The Impact of Individual Budgets on Social Care Providers in England. Social Policy and Administration 45, 593-612.

World Health Organisation (WHO) (2015) World report on ageing and health. WHO, Geneva. Zurbriggen, C. (2014) Governance: A Latin America perspective. Policy and Society 33, 34560. 
Table 1. Selected findings from national survey of residential LTC facilities (2013/14)

\begin{tabular}{|l|l|}
\hline Item & $\begin{array}{l}\text { Percent of care homes } \\
\text { surveyed (n=1803) }\end{array}$ \\
\hline Residents not permitted to personalise bedrooms & 43 \\
\hline Unsatisfactory appearance of residents (cleanliness, clothing, etc.). & 16 \\
\hline No flexibility in daily routine (eating, bathing, bedtime) & 13 \\
\hline Residents not permitted to go outside unattended & 44 \\
\hline Dirty appearance and unpleasant smelling & 11 \\
\hline Some bedrooms lacking windows & 17 \\
\hline No smoke detectors & 45 \\
\hline Unsatisfactorily heated & 24 \\
\hline Inadequate conditions of building & 31 \\
\hline Problematic noise levels & 61 \\
\hline No games available for residents & 31 \\
\hline
\end{tabular}

Source: Roqué et al (2016). 
Figure 1: Overall research design

\section{SCOPING AND MAPPING}

Document review

Key informant interviews $(n=10)$



January to March 2016

March to May 2016

June to July 2016

August 2016 to March 2017

March to September 2017 


\section{Care home interview guide}

1. Is there an identification sign on the street door? If yes, write the name and type of establishment as it appears on the sign.

2. Is the authorization certificate visible at the reception? If so, please state the authority that granted it and the dates of start and expiration.

3. Is there information about rights and responsibilities of residents on display?

4. Explain the reason for your visit to the establishment: you are looking for an institution to house your sister who has some behavioral problems and cannot manage in the house alone. You are looking with your niece for an appropriate residence for her. You need to write down what you are told and then discuss it with your niece.

5. How many older people live in this home?

6. Are there residents who are bed-bound? If so, how many?

7. Are there residents with dementia or other forms of cognitive impairment? If so, how many?

8. Who is in charge of the home? Indicate if they are the owner or a contracted profesional and if the owner has profesional qualifications. 
9. Which staff are in charge of the residents during the day? (indicate position, qualification and number)

10. At night, which staff are in charge? (indicate position, qualification and number)

11. Do they have any rules about who the will accept into the residence? (inquire if they accept people with cognitive problems or dependency)

12. Do they conduct interview the older person before admission? Or is the decision of a relative and that relative's agreement to the commerical terms of admission enough on their own for the person to be admitted?

13. Do they have a program to support the reception and adaptation of the older person to the residence?

14. Say your sister has a particular problem with falls. How they you deal with this type of problem?

15. How is the health of residents treated? (inquire if there is a dedicated doctor for the home and whether they are private or state funded)

16. What activities do they offer residents during the day?

17. How are the menus of each day decided? Are there special diets?

18. How many rooms does this care home have?

19. How many individual rooms do they have and how many are shared? Can you check them? (check if the doors are open, if there are people in bed when you enter and if residents' permission is requested before you enter) 
20. How many bathrooms are there? (check their privacy and cleanliness, etc.)

21. Where do residents eat (check if it is a dedicated dining area or if it also serves as a sitting room or television lounge)

22. Is there a sitting room? Is there a garden and somewhere to walk around?

23. In the shared rooms are residents able to dress with privacy? How?

24. Is there a room for multiple purposes and/or a rehabilitation room?

25. Have a general look around the care home. Ask about prices for different kinds of rooms and care arrangements 
26. Once you have left the care home, please complete this form:

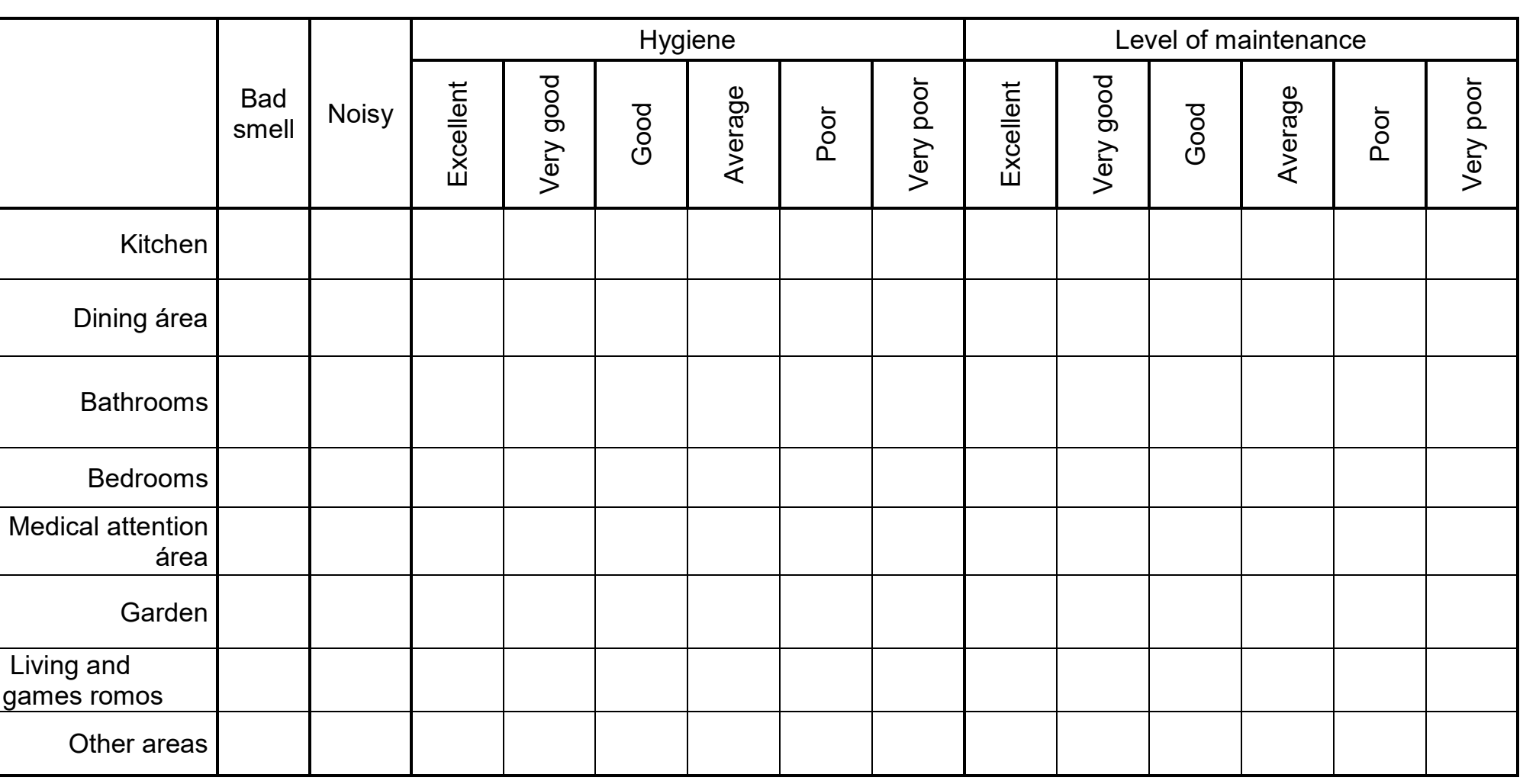

27. During your visit did you observe whether:

\begin{tabular}{|l|l|l|}
\hline The residents were & Yes & No \\
\hline Doing exercise & & \\
\hline Doing rehabilitation & & \\
\hline Doing occupational therapy & & \\
\hline Having lively conversations & & \\
\hline Walking with assistive devices & & \\
\hline Walking independently & & \\
\hline Using wheelchairs & & \\
\hline Reading or playing games & & \\
\hline Watching television & & \\
\hline In bed & & \\
\hline Physically restrainted & & \\
\hline Asleep & & \\
\hline
\end{tabular}

28. Please provide your overall impressions of this care home 